\title{
Behavior changes associated with lameness in sows
}

\author{
Ala-Kurikka, Eve
}

2017-04-01

Ala-Kurikka, E, Heinonen, M , Mustonen , K, Peltoniemi , O, Raekallio, M , Vainio , O \& Valros , A 2017 , ' Behavior changes associated with lameness in sows ' , Applied Animal Behaviour Science , vol. 193 , pp. 15-20 . https://doi.org/10.1016/j.applanim.2017.03.017

http://hdl.handle.net/10138/310834

https://doi.org/10.1016/j.applanim.2017.03.017

cc_by_nc_nd

acceptedVersion

Downloaded from Helda, University of Helsinki institutional repository.

This is an electronic reprint of the original article.

This reprint may differ from the original in pagination and typographic detail.

Please cite the original version. 


\section{Behavior changes associated with lameness in sows}

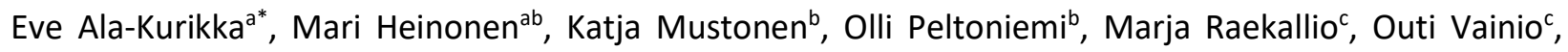
Anna Valros ${ }^{a}$

${ }^{a}$ Research Centre for Animal Welfare, Department of Production Animal Medicine, Faculty of Veterinary Medicine, University of Helsinki, PO Box 57, 00014 Helsinki, Finland

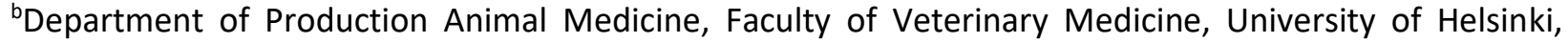
Paroninkuja 20, 04920 Saarentaus, Finland

${ }^{c}$ Department of Equine and Small Animal Medicine, Faculty of Veterinary Medicine, University of Helsinki, Koetilantie 2, FI-00014 University of Helsinki, Finland

*Corresponding author. Tel.: +358505170845. Email address: eve.ala-kurikka@helsinki.fi. 


\section{Keywords}

Sow, Lameness, Behaviour, Ketoprofen

\section{Abstract}

Lameness is a common health and welfare problem in sows. Very little research has been published about the behavioral changes in lame sows. Ketoprofen is an effective non-steroidal anti-inflammatory drug used in studies and in practice effectively in treating non-infectious locomotor disorders in pigs. The aim of this study was to determine the effect of lameness and lameness-related pain on the behavior of sows. To evaluate this effect, we studied whether pain alleviation with ketoprofen and clinical relief of lameness were associated with changes in behavior. We allocated randomly 13 lame, early pregnancy sows in three treatment groups receiving either ketoprofen $4 \mathrm{mg} / \mathrm{kg}$, ketoprofen 2 $\mathrm{mg} / \mathrm{kg}$ (these two groups were pooled for statistical analyses) or placebo. The animals were treated orally for 5 days and lameness scored before and on the last day of the treatment. Lameness was assessed with a 5-grade scoring system and behavior by scan sampling method. A clinically healthy, nonlame control sow was selected for each lame sow and they were examined the same way as lame sows but received no treatment. Lame sows were more passive, they lay more and stood and explored pen fixtures less than the control sows before treatment. After 5-days treatment, placebo-treated sows were in contact with the wall and lying more when compared to control sows. Ketoprofen-treated sows were more seldom in contact with the wall and exploring bedding more often than placebo-treated sows. Placebo sows tended also to move and explore bedding less than control sows. Lameness had been relieved in altogether 7 out of 13 sows on day 5: six out of nine ketoprofen-medicated sows and one out of four placebo-treated sows. The behaviour of sows with relieved lameness did not differ from control sows on day 5. Sows with non-relieved lameness were in contact with the wall and lying more and moving and standing less than control sows. When compared to control sows, sows with non-relieved 
lameness tended to be more passive $(P=0.06)$. When compared to sows with relieved lameness, sows with non-relieved lameness showed a tendency to be in contact with the wall more $(P=0.07)$. Our study showed that lameness reduces the activity of sows and affects their position in the pen. Passive behavior seemed at least partly be due to pain and the recovery of lameness was connected to normalization of the behavior.

\section{Introduction}

Lameness is a common health problem in sows: its prevalence has been reported to range from $8.8 \%$ to 16.9 \% (Heinonen et al., 2006; KilBride et al., 2009). Lameness causes economic losses and is a major reason for unplanned culling of sows (Engblom et al., 2008; Kirk et al., 2005). It is also an important welfare issue (Heinonen et al., 2013) and has been identified as an animal-based welfare measurement in The European Welfare Quality ${ }^{\circledR}$ program (2011).

According to Black's Veterinary Dictionary (2015) lameness is defined as departure from normal gait, usually accompanied by pain. Lameness is not a single disease but rather a clinical sign associated with a range of conditions (Potterton et al., 2012). The causes of lameness are various, including claw lesions, trauma, osteochondrosis, fractures, skin lesions and arthritis (Dewey et al., 1993; Heinonen et al., 2006). The exact reason for lameness in sows is very difficult to diagnose in herd-level clinical examinations (Dewey et al., 1993), thus lameness of sows is often used as a general diagnosis in both swine practice and in scientific swine research.

Typical behavioral changes in connection to acute illness in animals include a reduction in activity, social interaction, feeding and drinking behavior, as well as an increase in huddling, shivering and resting (Millman, 2007). Lameness can be expected to cause behavioral changes due to physically reduced locomotion ability, pain or general discomfort and sickness behavior (Heinonen et al., 2013). Lame sows have been reported to show an increased incidence of uncontrolled lying-down behavior (Bonde et al., 
2004)a decreased frequency of standing and an increased frequency of lying postures (Pairis-Garcia et al., 2015) in comparison with non-lame sows. Furthermore, Cornou et al. (2008) showed that changes in the feeding behavior of lame sows could be used as an indicator of lameness.

In practice, pain in pigs is usually treated with non-steroidal anti-inflammatory drugs (NSAIDs). However, there is probably still a lack of adequate pain alleviation for lame pigs on some farms. A survey by Ison and Rutherford (2014) conducted in the UK in 2012 - 2013 found that all veterinarians used NSAIDs to treat pigs with lameness, whereas one quarter of the farmers did not use any pain medication. The authors found that time and practicality of giving drugs, the cost of the products, attitudes, poor communication between farmers and veterinarians and lack of knowledge were potential barriers to the increased use of pain relief in pigs. A number of NSAIDs are licensed for the treatment of painful conditions in pigs in the EU (European Medicines Agency). The NSAIDs ketoprofen and meloxicam have been reported to be effective in treating non-infectious locomotor disorders of sows and pigs (Friton et al., 2003; Mustonen et al., 2011). Ketoprofen is well absorbed in pigs and its bioavailability is almost complete after oral administration (Raekallio et al., 2008).

The objective of this study was to determine the effect of lameness and lameness-related pain on the behavior of sows. Our hypotheses were that lame sows are less active than healthy sows (e.g. they move and explore less), and if lameness were caused by pain, administration of analgesics for lame sows would reduce or stop these behavioral changes. To evaluate the effect of pain and lameness on sow behavior, we studied whether pain alleviation with ketoprofen and clinical relief of lameness were associated with changes in behavior.

\section{Materials and methods}

\subsection{Animals and housing}


The data were collected from a commercial piglet-producing farm with 950 sows in southern Finland in 2008. The study was conducted in parallel with and using a subset of the same sows for a study investigating the effect of ketoprofen for treating lame sows (Mustonen et al., 2011).

Sows were observed in the dry sow unit. All sows and gilts, which had been inseminated at least once, were regarded as eligible for the study. Sows pregnant for $>100$ days and animals medicated with nonsteroidal anti-inflammatory drugs (NSAIDs), glucocorticoids or antibiotics within 14 days before the start of the trial were excluded from the study.

Two veterinarians independently assessed and scored lameness (Table 1) of the sows on day 0 . For lameness scoring the sows were taken out from the pen one by one and walked on a gangway on a hard, solid floor of least 10 meters. The sows were driven to walk by clapping them on the back and guiding with plastic board. The sows with a score $\geq 2$ identically assessed by both veterinarians were included in the study as lame sows. After the lameness evaluation, the veterinarians performed a clinical examination, including measuring rectal temperature, of each sow. Only animals clinically diagnosed as having non-infectious cases of lameness were included. If the sow had fractures, infected wounds, a rectal temperature over $39.5^{\circ} \mathrm{C}$ or any concurrent disease, she was excluded. A blood sample was taken from each study animal and measured as described in the study of Mustonen et al. (2011). After this, the sows were taken back to their pens.

A clinically healthy, non-lame (lameness score 0 , assessed by both veterinarians) control sow at the same stage of pregnancy was selected as a partner for each lame sow from the same pen. The control animals were examined exactly as for lame sows. We were able to score the lameness of only about 100 sows in one day; we included in the study every eligible sow, which we managed to find and sample during a one day farm visit. 
As a result of the selection method, the study animals included 13 lame and 13 clinically healthy control sows. The study animals were group-housed with other sows in their home pens, and under the normal management practices of the farm during the study. The study animals originated from nine pens in the dry sow unit. There was one pair of study sows in six pens and 2-3 pairs in three pens. All the pens ( 30 $\mathrm{m}^{2}$ ) were similar, housed 9-11 sows, and had solid walls. Two-thirds of the pen floor was solid concrete, covered with $0.5-1 \mathrm{~cm}$ layer of chopped straw, and one-third of the floor was concrete slats. Sows were fed according to normal farm practice with a commercial dry sow feed twice daily at approximately 06:30 and 13:30. Sows were fed from a through, divided by short walls into individual feeding places of $50 \mathrm{~cm}$ per sow. Water was freely available from one cup per pen.

The median stage of pregnancy of the sows on the day of lameness scoring (day 0) was 44 days (range: 28-51). The body condition scores of sows included in the study were 3-4 (using scale 1-5) and their mean parity was 2.1 (range: $0-7$ ). The lameness scores of the lame sows were $2-3$. There were no statistical differences in number of parities or lameness scores across the treatment groups on day 0. The sows were various crossbreeds of Yorkshire, Finnish Landrace and Norwegian Landrace.

\subsection{Treatment}

The lame sows ( $n=13$ ) were allocated randomly to one of the following treatment groups: (1) ketoprofen $4 \mathrm{mg} / \mathrm{kg}(\mathrm{n}=4),(2)$ ketoprofen $2 \mathrm{mg} / \mathrm{kg}(\mathrm{n}=5),(3)$ placebo $(n=4)$. The randomization was done by drawing numbers randomly. Ketovet vet $2.4 \mathrm{~g}$ oral powder (Provivo) was used as the test product for the $4 \mathrm{mg} / \mathrm{kg}$ dose and a mixture of Ketovet vet $2.4 \mathrm{~g}$ oral powder and placebo in a 1:1 ratio for the $2 \mathrm{mg} / \mathrm{kg}$ dose. The placebo contained $14 \mathrm{~g}$ of maltodextrine and $1 \mathrm{~g}$ of carmellose sodium. The University Pharmacy of Helsinki manufactured the $2 \mathrm{mg} / \mathrm{kg}$ mixture and placebo and re-packed and labeled all sachets. The veterinarian prepared all daily doses in separate bottles and trained the owner to mix the powder with tap water and to administer it to the test animals. The owner gave the medication directly into the sow's 
mouth with a $20 \mathrm{ml}$ syringe, each day for five days (days 1 to 5), starting from the day after the first lameness scoring. The veterinarians and the herd personnel were blinded to the treatments throughout the study. The healthy control sows received neither medication nor placebo.

\subsection{Evaluation of the outcome}

On the fifth treatment day (day 5) the sows were again scored for lameness and examined exactly as described in subsection 2.1. The same veterinarians as on day 0 made the lameness scoring and examinations. The efficacy of the treatment was assessed according to the lameness score of the sows on day 5. Scores 0 and 1 were regarded as indicating relief from lameness.

\subsection{Behavioural data}

Two persons blinded to the lameness or treatment status of the sows monitored their behavior using a scan-sampling method with 5-min intervals for 2 hours, providing 24 observations per sow per day. The 2-hour scan-samplings were done twice: before medication on day 0 and after the fifth medication on day 5, starting 10 minutes after afternoon feeding. An ethogram modified from Munsterhjelm et al. (2008) was used (Table 2). The sows were marked with animal spray on their backs to enable individual identification. The observers were positioned in the alley between the pens and before the start of the observation they walked three times through the alley to let the sows get used to them. During the observation a sow's position in the pen was recorded first, then her posture and thirdly the type of activity (Table 2).

\subsection{Statistical analysis}

Behavioral data were investigated as number of observations for each behavior. For statistical analysis, results for ketoprofen doses of $2 \mathrm{mg} / \mathrm{kg}$ and $4 \mathrm{mg} / \mathrm{kg}$ were pooled because no difference was detected in treatment success between the doses when evaluated in a study with 93 sows (Mustonen et al., 2011). 
The 13 lame sows in this study were a subset of those 93 sows. Statistical analyses were performed using SPSS software (IBM SPSS Statistics for Macintosh, Version 21.0. Armonk, NY: IBM Corp). The data were analyzed using nonparametric Mann-Whitney U-tests because they were not normally distributed. On day 5, three groups (according to treatment and relief from lameness) were first compared using Kruskal-Wallis tests, and those behaviors where $p<0.1$ were selected for pairwise analysis with MannWhitney U-tests. Only significant results $(p<0.05)$ and tendencies $(p<0.1)$ are reported.

\section{Results}

A summary of all observed behaviors of the 26 sows before the treatments on day 0 is presented in Table 2. As shown in Figure 1, lame sows were observed to be more passive, to lie down more and stand and explore pen fixtures less than the control sows on day 0 . There were no significant differences in any other behaviors between the groups on day 0 .

Treatment effects $(p \leq 0.05)$ on the behavior of the sows on day 5 are shown in Figure 2 . When compared with control sows, placebo-treated sows were observed to be in contact with the wall and to lie down more. Ketoprofen-treated sows were observed less in contact with the wall and explored bedding more than placebo-treated sows. In comparison with control sows, ketoprofen-treated sows were lying down more and standing less. The sows that were treated with placebo tended to move and explore bedding less than control sows $(p=0.08)$. Otherwise there were no differences in behavior across the three treatment groups.

Lameness was relieved in seven of 13 sows on day 5: in six of nine ketoprofen-medicated sows and in one of four placebo-treated sows. Significant effects of the outcome on the behavior of sows on day 5 are provided in Figure 3. Sows with non-relieved lameness were in contact with the wall and lying down more, while moving and standing less than control sows. When compared with control sows, sows with 
non-relieved lameness tended to be more passive $(p=0.06)$ and when compared with sows with relieved lameness, sows with non-relieved lameness showed a tendency to be in contact with the wall more often ( $p=0.07)$. No other differences were evident in behavior among the groups.

\section{Discussion}

Our study reports differences in the behavior of lame sows compared with healthy ones. In addition, we established effects of ketoprofen treatment on behavior, as compared with a placebo treatment, and when comparing sows with respect to relief of lameness. The results supported our hypotheses that lame sows were generally more passive than healthy sows. Ketoprofen treatment both alleviated lameness and affected some behaviors of the lame sows, indicating that, at least in these sows, there was pain involved with the lameness. Even though the study was conducted with a rather small sample size, and it should be replicated with a larger sample size to verify the conclusions, some statistically significant differences could be detected and the results are novel and interesting.

As expected, lame sows were more passive, lying more and standing and exploring less than healthy sows. Escobar et al. (2007) reported that pigs with an acute PRRSV infection decreased their activity and lay down more. The overall activities of pigs also decreased during acute sarcocystosis infection (Reiner et al., 2009). Sickness behavior associated with infection is well documented (Hart 1988). Our results, in agreement with other studies, indicate that a rather similar behavioral response is also seen in connection with non-infectious lameness. In the study of Parsons et al. (2015) lameness was induced in sows using a chemical synovitis model, and it was found that sows were standing less after the lameness induction. Similarly, sows with more severe claw lesions had higher frequency of lying posture and lower frequency of standing posture than sows with healthier claws (Enokida et al., 2011).

In our study, giving analgesics to lame sows reduced the behavioral differences between lame and healthy sows as seen before treatment. This indicates that lame sows were in pain and that the sows 
responded positively to the ketoprofen treatment. However, three of nine lame sows that were administered ketoprofen did not show a similar response. Our aim was to enroll only sows with noninfectious lameness in the study, and without any concurrent disease, but we did not have specific diagnoses for the lame sows. Albeit non-infectious, the cause of lameness could have arisen from various sources, such as anatomical impairment, ostechondrosis or claw disorders (Dewey et al., 1993). It could be interpreted that the non-resolved lameness was not due to pain initially or that ketoprofen was not effective in treating pain in those cases. To confirm this, further studies involving more detailed diagnoses and e.g. post mortem data is needed.

Sows with non-resolved lameness on day 5 of the treatment were observed to move and stand less and lie down more than healthy control sows. They were also in contact with the wall more than healthy sows. These differences in behavior could be interpreted as signs of pain. At the group-level, ill and injured individuals represent a vulnerable population with unique needs and preferences (Millman, 2007). The preference of sows with non-relieved lameness to stay in contact with the wall could also be interpreted as a way of seeking shelter and isolation from the group. In this way other sows in the group were probably not able to attack the sow lying next to the wall and protecting herself. Sows might have perhaps learnt to stay in one place to avoid particular social situations in the group, if their lameness had lasted several days. Regrettably, however, we do not know for how long before day 0 the lame sows had been lame, if at all. Preference studies could be used to evaluate possible changes in the preferred pen location of animals in pain (Weary et al., 2006), but to our knowledge no such studies are available for lame pigs. The location of the lame sows in the pen was observed in the study of Parsons et al. (2015), but it was not recorded if the sows were in contact with the pen wall. Anyway, the findings for behavior of sows with non-relieved lameness may be important when interpreting the special needs of lame sows in relation to pen surroundings. We thus suggest that hospital and recovery pens should offer 
lame sows the possibility to isolate themselves from the group, to lie comfortably near the wall and to eat and drink without having to move much.

Overall, the sows in the present study were very passive, including the healthy control sows. Any movement was considered activity in our study, which is typical for defining activity in applied ethology research (Fureix and Meagher, 2015). Healthy outdoor sows spend an average value of $21 \%$ of their day active (Buckner et al., 1998). As the scan-sampling started 10 minutes after feeding, one explanation for the inactivity of the sows in our study could be post-prandial inactivity associated with satiety, as reported by Zonderland et al. (2004). However, Buckner et el. (1998) found a contradictory activity peak of sows post feeding in the morning. A bimodal diurnal activity of pigs with activity peaks on the morning and before sunset has been reported in many papers (Buckner et al., 1998). In our study, we observed the pigs only for two hours in the afternoon, which might not have been optimal for detecting the most active phase of the sows. Alternatively, it is possible that the pen surroundings were not enriched enough, although they did meet legal requirements, to stimulate active behavior of sows. In further behavior studies more attention should be paid to inactivity of sows because it is a potential indicator of welfare and affective states and could even be associated with boredom-like conditions (Fureix and Meagher, 2015).

\section{Conclusions}

Results of this study indicated that lameness reduced the activity of sows. Passive behavior was at least partly due to pain because pain alleviation diluted the behavioral changes associated with lameness. Alleviation of lameness was associated with normalization of the behavior. These findings may be useful when formulating recommendations for treatment of lameness and pain in sows. 


\section{Conflict of interest}

The authors of this paper have no financial or personal relationship with people or organizations that could inappropriately influence or bias the content of the paper.

\section{Acknowledgements}

This study was funded by the Orion-Farmos Research Foundation, the Academy of Finland, the Mercedes Zachariassen Foundation, Vetcare, LSO Foods, Snellman, Suomen Rehu and Atria. The study medications were donated by Vetcare. The foundations and companies were not involved in any aspect of this research project. The farm personnel is acknowledged for co-operation and providing the animals for the study.

\section{References}

Boden, E., Andrews, A., 2015. Black's Veterinary Dictionary, $22^{\text {nd }}$ ed. Bloomsbury, London, England.

Bonde, M., Rousing, T., Badsberg, J.H., Sørensen, J.T., 2004. Associations between lying-down behaviour problems and body condition, limb disorders and skin lesions of lactating sows housed in farrowing crates in commercial sow herds. Livest. Prod. Sci. 87, 179-187.

Buckner, L.J., Edwards, S.A., Bruce J.M., 1998. Behaviour and shelter use by outdoor sows. Appl. Anim. Behav. Sci. 57, 69-80.

Cornou, C., Vinther, J., Kristensen, A.R., 2008. Automatic detection of oestrus and health disorders using data from electronic sow feeders. Livest. Sci. 118, 262-271.

Dewey, C.E., Friendship, R.M., Wilson, M.R., 1993. Clinical and postmortem examination of sows culled for lameness. Can. Vet. J. 34, 555-556. 
Engblom, L., Lundeheim, N., Strandberg, E., Schneider Mdel, P., Dalin, A.M., Andersson, K., 2008. Factors affecting length of productive life in Swedish commercial sows. J. Anim. Sci. 86, 432-441.

Enokida, M., Sasaki, Y., Hoshino, Y., Saito, H., Koketsu, Y., 2011. Livest. Sci. 136, 256-261.

Escobar, J., Van Alstine, W.G., Baker, D.H., Johnson, R.W., 2007. Behaviour of pigs with viral and bacterial pneumonia. Appl. Anim. Behav. Sci. 105, 42-50.

European Medicines Agency, Veterinary Regulatory. Maximum residue limit assessment reports. http://www.ema.europa.eu/ema/index.jsp?curl=pages/medicines/landing/vet_mrl_search.jsp \&mid=WC0b01ac058006488e. (accessed 11.02.2017)

Friton, G.M., Philipp, H., Schneider, T., Kleemann, R., 2003. Investigation on the clinical efficacy and safety of meloxicam (MetacamReg.) in the treatment of non-infectious locomotor disorders in pigs. Berl. Munch. Tierarztl. Wochenschr. 116, 421-426.

Fureix, C., Meagher, R.K., 2015. What can inactivity (in its various forms) reveal about affective states in non-human animals? A review. Appl. Anim. Behav. Sci. 171, 8-24. doi: 10.1016/j.applanim.2015.08.036.

Hart, B.L., 1988. Biological basis of the behavior of sick animals. Neurosci. Biobehav. Rev. 12, 123-137.

Heinonen, M., Oravainen, J., Orro, T., Seppa-Lassila, L., Ala-Kurikka, E., Virolainen, J., Tast, A., Peltoniemi, O.A.T., 2006. Lameness and fertility of sows and gilts in randomly selected loose-housed herds in Finland. Vet. Rec. 159, 383-387.

Heinonen, M., Peltoniemi, O., Valros, A., 2013. Impact of lameness and claw lesions in sows on welfare, health and production. Livest. Sci. 156, 2-9. 
KilBride, A.L., Gillman, C.E., Green, L.E., 2009. A cross-sectional study of the prevalence of lameness in finishing pigs, gilts and pregnant sows and associations with limb lesions and floor types on commercial farms in England. Anim. Welfare. 18, 215-224.

Kirk, R.K., Svensmark, B., Ellegaard, L.P., Jensen, H.E., 2005. Locomotive disorders associated with sow mortality in Danish pig herds. J. Vet. Med. A Physiol. Pathol. Clin. Med. 52, 423-428.

Millman, S.T., 2007. Sickness behaviour and its relevance to animal welfare assessment at the group level. Anim. Welfare. 16, 123-125.

Munsterhjelm, C., Valros, A., Heinonen, M., Hälli, O., Peltoniemi, O., 2008. Housing during early pregnancy affects fertility and behaviour of sows. Reprod. Domest. Anim. 43, 584-591.

Mustonen, K., Ala-Kurikka, E., Orro, T., Peltoniemi, O., Raekallio, M., Vainio, O., Heinonen, M., 2011. Oral ketoprofen is effective in the treatment of non-infectious lameness in sows. Vet. J. 190, 55-59.

Potterton, S.L., Bell N.J., Whay, H.R., Berry, E.A., Atkinson, O.C.D., Dean, R.S., Main, D.C.J., Huxley, J.N., 2012. A descriptive review of the peer and non-peer reviewed literature on the treatment and prevention of foot lameness in cattle published between 2000 and 2011. Vet. J. 193, 612-616.

Raekallio, M.R., Mustonen, K.M., Heinonen, M.L., Peltoniemi, O.A.T., Sakkinen, M.S., Peltoniemi, S.M., Honkavaara, J.M., Vainio, O.M., 2008. Evaluation of bioequivalence after oral, intramuscular, and intravenous administration of racemic ketoprofen in pigs. Am. J. Vet. Res. 69, 108-113.

Reiner, G., Hübner, K., Hepp, S., 2009. Suffering in diseased pigs as expressed by behavioural, clinical and clinical-chemical traits, in a well defined parasite model. Appl. Anim. Behav. Sci. 118, 222-231.

Weary, D.M., Lee, N., Flower, F.C., Fraser, D., 2006. Identifying and preventing pain in animals. . Appl. Anim. Behav. Sci. 100, 64-76. 
Zonderland, J., de Leeuw, J., Nolten, C., Spoolder, H., 2004. Assessing long-term behavioural effects of feeding motivation in group-housed pregnant sows; what, when and how to observe. Appl. Anim. Behav. Sci. 87, 15-30.

Welfare Quality ${ }^{\circledR}, 2009$. Welfare Quality ${ }^{\circledR}$ assessment protocol for pigs (sows and piglets, growing and finishing pigs). Welfare Quality ${ }^{\circledR}$ Consortium, Lelystad, Netherlands. 
Table 1. Lameness scoring system used to assess lameness in pregnant sows in a study estimating behavioral changes associated with lameness in sows.

\begin{tabular}{lll}
\hline Score & Lameness & Clinical signs \\
\hline 0 & None & $\begin{array}{l}\text { No lameness } \\
1\end{array}$ \\
2 & Minimal & $\begin{array}{l}\text { Stiff, ataxic or swaying gait, shortened stride } \\
\text { Slimp visible, but animal unconcerned and exercises } \\
\text { normally }\end{array}$ \\
3 & Moderate & $\begin{array}{l}\text { Obvious limp present all the time (with head bobbing), } \\
\text { animal having some difficulty with exercise, moderate } \\
\text { kyphotic posture }\end{array}$ \\
4 & Severe & $\begin{array}{l}\text { Animal barely weight bearing/not weight bearing, } \\
\text { severely lame but able to move, severe kyphotic posture }\end{array}$
\end{tabular}


Table 2. The ethogram used for scoring sow behavior by 5 min scan-sampling for 2 hours (modified from Munsterhjelm et al. 2008) and descriptive statistics for the observed behaviors in 26 pregnant sows included in a study investigating the association between behavior and lameness. Positions (except 'in contact with the wall'), postures and activities formed three mutually exclusive behavior categories. Day $0=$ the first day of the study follow-up.

\begin{tabular}{|c|c|c|}
\hline Behavior & Description & $\begin{array}{l}\text { Number of observations } \\
\text { per sow on day } 0, \\
\text { median (range;sum) }\end{array}$ \\
\hline Position in the pen & $\begin{array}{l}\text { Defined as where at least } 50 \% \text { of the animal is } \\
\text { positioned. }\end{array}$ & \\
\hline On the solid floor & & $20(11-24 ; 521)$ \\
\hline On the feeding area & & $1(0-5 ; 50)$ \\
\hline On the slatted floor & & $1(0-12 ; 53)$ \\
\hline $\begin{array}{l}\text { In contact with the } \\
\text { wall }\end{array}$ & $\begin{array}{l}\text { Some part of the animal is touching wall. Sows } \\
\text { could be in contact with the wall in all pen } \\
\text { positions listed above. }\end{array}$ & $18(1-24 ; 391)$ \\
\hline \multicolumn{3}{|l|}{ Posture } \\
\hline Lying & Lying down on the sternum or on one side & $19(8-23 ; 470)$ \\
\hline Standing & Standing on all four legs without moving & $4(1-15 ; 132)$ \\
\hline Sitting & $\begin{array}{l}\text { Sitting on the tail with the forelegs stretched } \\
\text { straight under the body }\end{array}$ & $0(0-4 ; 7)$ \\
\hline Moving & $\begin{array}{l}\text { Walking or running across the pen, jumping, } \\
\text { frisking }\end{array}$ & $0(0-2 ; 12)$ \\
\hline \multicolumn{3}{|l|}{ Activity } \\
\hline Eating & $\begin{array}{l}\text { Head in the feeder or chewing feed (not } \\
\text { bedding) }\end{array}$ & $1(0-5 ; 48)$ \\
\hline Drinking & Use of water cup for drinking & $0(0-2 ; 10)$ \\
\hline Exploring substrate & $\begin{array}{l}\text { Nosing, sniffing, touching, licking, chewing, } \\
\text { sucking or rooting beddings }\end{array}$ & $1(0-7 ; 40)$ \\
\hline Exploring the pen & $\begin{array}{l}\text { Nosing, sniffing, touching, licking, chewing, } \\
\text { sucking or rooting any part of the pen or floor }\end{array}$ & $0(0-2 ; 10)$ \\
\hline Nosing/ being nosed & $\begin{array}{l}\text { Sniffing or touching any body part of other sow } \\
\text { with the snout, no attempt to push/ Being the } \\
\text { recipient of nosing }\end{array}$ & $\begin{array}{c}0(0-1 ; 5) / \\
0(0-3)\end{array}$ \\
\hline Walking & $\begin{array}{l}\text { Moving forward without simultaneously doing } \\
\text { any of the above listed activities }\end{array}$ & $0(0-2 ; 11)$ \\
\hline Passive & Performing no activity (sleeping, watching etc.) & $19(11-23 ; 485)$ \\
\hline
\end{tabular}




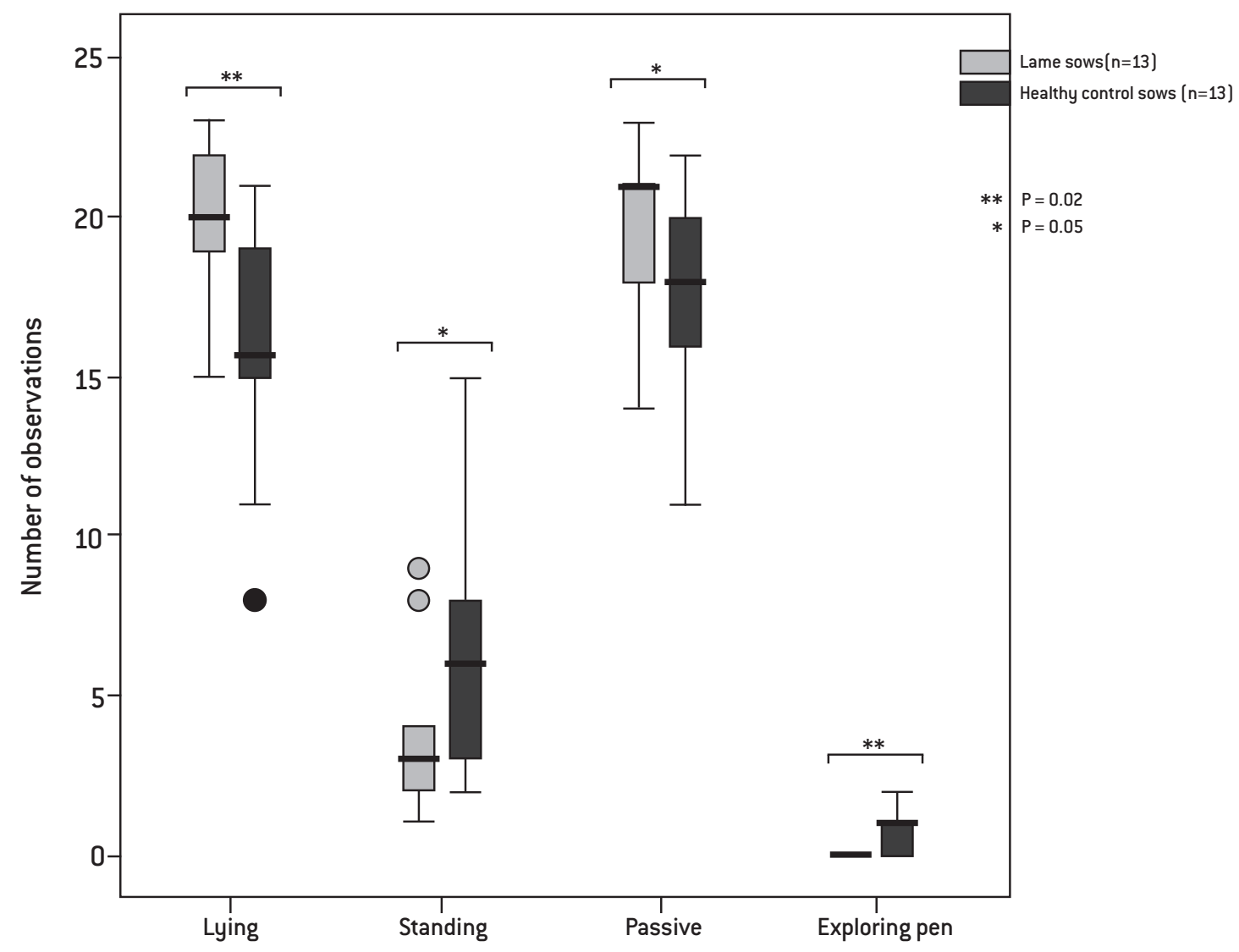

Figure 1. The behavior of 13 lame and 13 healthy control sows on the first day of the study. Only behaviors that differ between lame and controls are presented $(* P=0.05, * * P=0.02)$. Sow behavior was recorded every 5 minutes for 2 hours by direct observation. Numbers of observations are given as median, lower and upper quartiles and range. Dots represent outliers. 


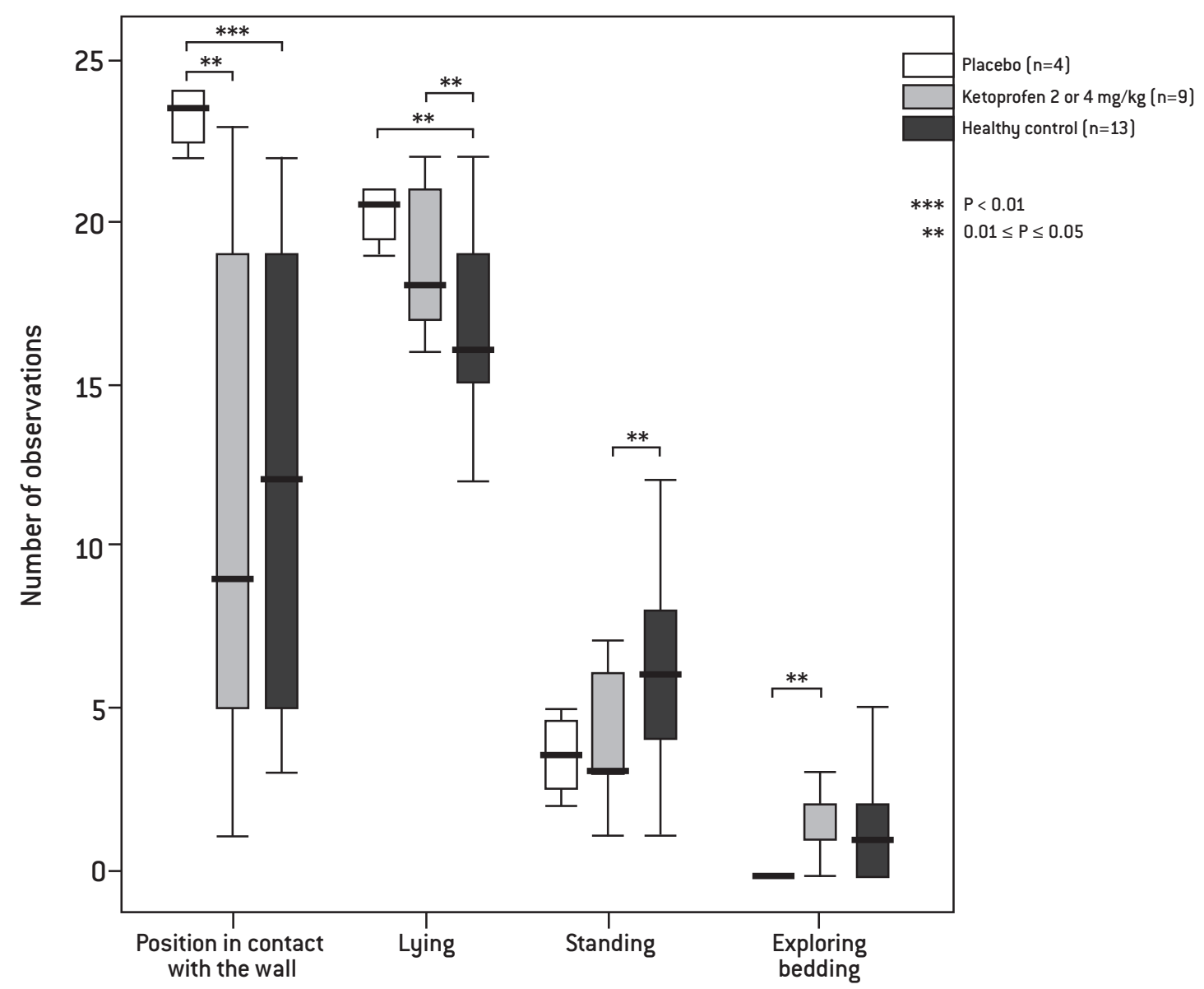

Figure 2. The behavior of 13 lame sows after treating them with oral ketoprofen ( 2 or 4 $\mathrm{mg} / \mathrm{kg}$ ) or placebo. Thirteen control sows represent a healthy untreated group. Only behaviors, which differ between the treatment groups, are presented $(* * 0.01 \leq P \leq 0.05$, $* * * P<0.01)$. The behavior was recorded every 5 minutes for 2 hours by direct observation. Numbers of observations are given as median, lower and upper quartiles and range. 


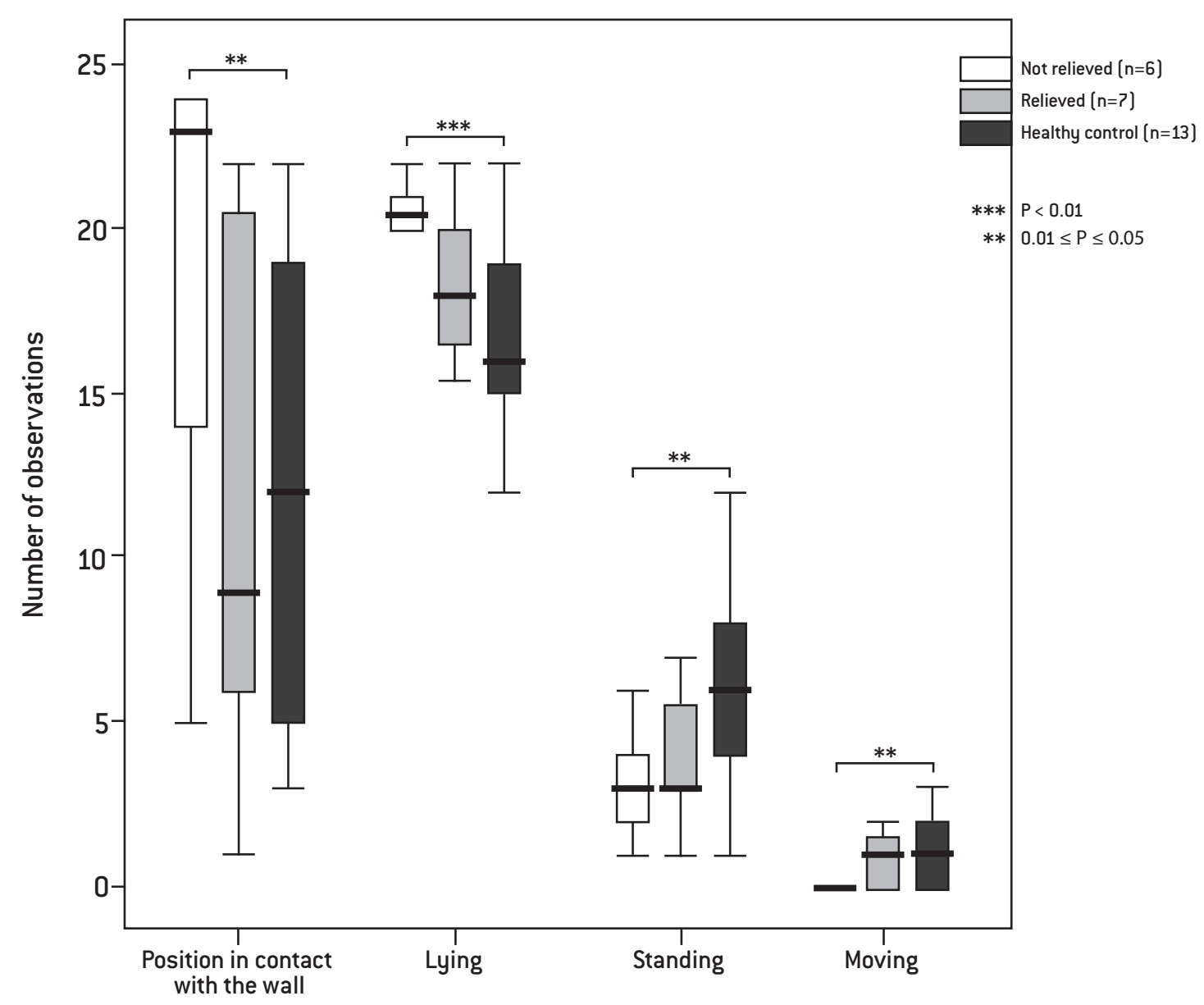

Figure 3. The behavior of 13 lame sows after grouping them according to the outcome (not relieved/ relieved) of the 5-day treatment, regardless of the treatment group (ketoprofen 2 or $4 \mathrm{mg} / \mathrm{kg}$ or placebo): Seven not relieved sows were still considered lame and six relieved sows had become non-lame. Thirteen control sows represent a constantly non-lame, untreated group. The behavior was recorded every 5 minutes for 2 hours by direct observation. Numbers of observations are given as median, lower and upper quartiles and range. 